\title{
Why Do Mothers Die? The Silent Tragedy of Maternal Mortality
}

\author{
Pascale Baraté* and Marleen Temmerman
}

\author{
International Centre for Reproductive Health (ICRH), Department of Obstetrics and Gynaecology, Ghent University, \\ Belgium
}

\begin{abstract}
More than two decades after the launch of the Safe Motherhood Initiative, maternal health in many developing countries has shown little or no improvement. Year after year, more than half a million mothers continue to die in silence. The specificities of the complex cross-cutting issue only partly explain why tireless efforts have led to insufficient progress so far. While some success stories prove that results can be obtained quickly, the dissensions and deficiencies the Initiative has encountered have strongly weakened its impact.

However, recent developments over the past 3 years allow us to foresee the silence will soon be broken. While advocacy begins to subsequently raise awareness, more financial means are mobilized. As a consensus on the priority interventions has finally been reached (Women Deliver conference, London, October 2007), more coordinated actions and initiatives are being developed. The strive for the achievement of the Millennium Development Goals helps to create the political momentum the cause strongly needs to generate new leadership, develop and implement the adequate strategies. Sensible focus on resources and structure as well as innovative management will be crucial in that process.
\end{abstract}

Keywords: Maternal mortality, women's health, MDG5, health system, systemic approach, developing countries.

\section{INTRODUCTION}

We felt compelled to write this article as recent developments in the Maternal Neonatal and Child Health sphere raise hope for significant advances in the near future but also apprehensions about possible confused and ineffective courses of action.

Since the launch of the Safe Motherhood Initiative in 1987 substantial progress has been made in both the investigation and the documentation of maternal deaths. Numerous articles, reports and books have been written on maternal mortality and there is little reason to replicate what they clearly state. The Reproductive Health Matter 1999 special issue on Safe Motherhood, the European Commission book on Safe Motherhood strategies, a review of the evidence (2001), the 2005 World Health Report "Making every Mother and Child count" (WHO), the Lancet on Maternal Survival Series (September 2006) and the Lancet edition published during the Women Deliver Conference in London (October 2007) compile key data, opinions, trends and references we invite you to read. Therefore this article does not detail or extensively describe all parameters and issues but rather focuses on the elements that appear relevant to the latest and future evolvements.

After a few facts and figures, we look into the specificities and root causes that make this plague so difficult to manage. Before evoking the progress already made as well as that still to come in reaching the targets set by the fifth Millennium Development Goal, we look over the obstacle course that the cause has been through during the last twenty-two years. Finally, in light of what is currently

*Address correspondence to this author at the International Center for Reproductive Health (ICRH), Ghent University, Belgium; Tel: +32476340336; Fax: +3234822504; E-mails: pbarate@hotmail.com,Pascale.Barate@UGent.be needed to improve maternal health worldwide, we point out priority actions to limit chances of slow and ephemeral progress and identify questions for future research into sources of efficient maternal health policy implementation.

\section{BACKGROUND}

1450 women die each day from avoidable causes [1].

$86 \%$ of maternal deaths occur in Sub-Saharan Africa and in South Asia (Fig. 1).

Year after year, more than half a million of mothers continue to die from the same causes identified by the WHO 20 years ago [2]. The direct and indirect causes of maternal mortality have not altered substantially although the HIV pandemic is having a prejudicial effect.

WHO lists severe bleeding/haemorrhage (25\%), infections (13\%), unsafe abortions (13\%), hypertension (12\%), obstructed labour (8\%), other direct causes (8\%), and indirect causes (20\%). Indirect causes such as malaria, anaemia, HIV/AIDS and cardiovascular disease, either complicate pregnancy or are aggravated by it $[3,4]$.

The birth period - before, during and after - is the time when mortality and morbidity risks are highest for both mother and child. More than $61 \%$ of maternal deaths happen during or shortly after delivery. Difficult childbirth is a major cause of death among newborn children. Some 3.4 million newborns die within the first week of life.

Pregnancy-related complications are among the leading causes of death and disability for women between the ages of 15-49 in developing countries. Currently the lifetime risk of maternal death (the probability of maternal death during a woman's reproductive life) is highest in Africa (at 1 in 26). In certain countries, the lifetime risk is greater than 1 in 10 $[5,6]$. The distribution of risk rates demonstrates drastic 


\section{Maternal deaths per 100,000 live births, 2005}

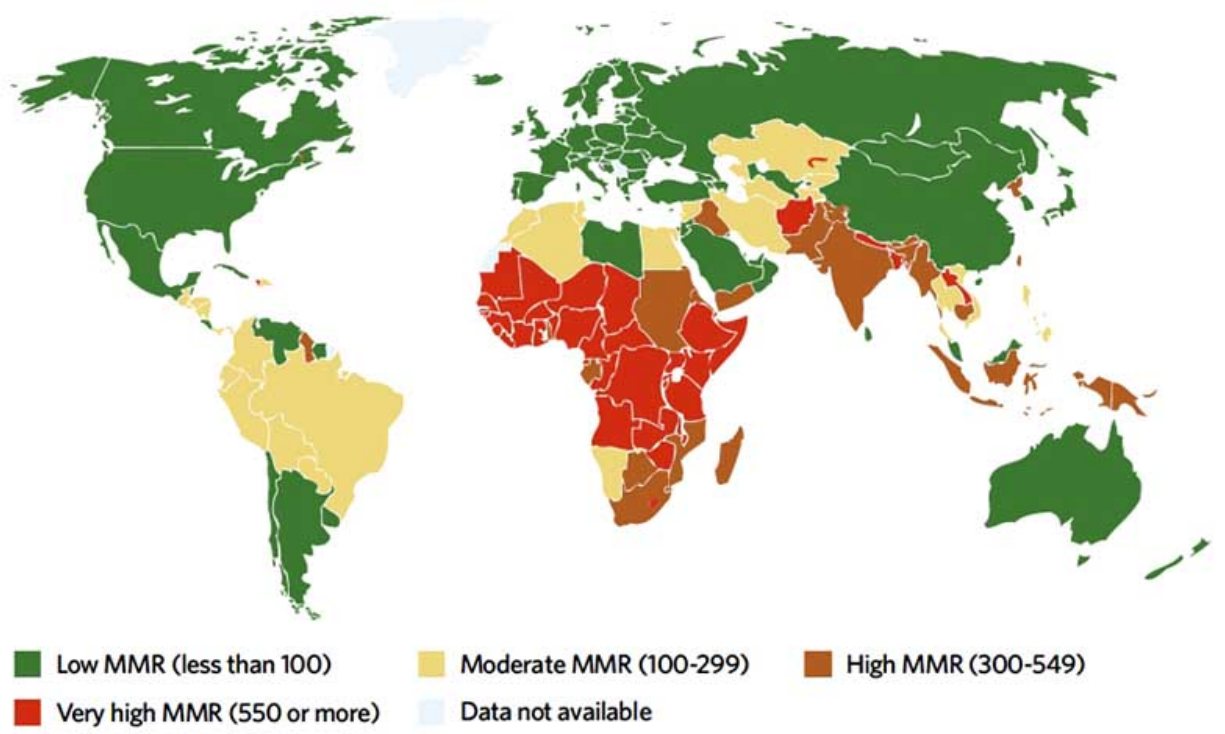

Fig. (1). Maternal mortality ratio, by country, 2005.

contrasts; it is one in eight in Afghanistan and 1 in 47.600 in Ireland [7].

For every woman who dies, 20 or more women suffer severe morbidity (injury, infection or disease). Maternal health is more than avoiding death; it includes preventing conditions like obstetric fistula, transmission of infections, infertility and depression. Morbidity related to pregnancy and childbirth reaches more than 10 million women annually [3].

Most of these appalling statistics have remained relatively unchanged for 20 years; facts which are deeply shocking considering almost all cases of maternal mortality are preventable.

Safe motherhood is about ensuring that all women receive the care they need to be safe and healthy throughout pregnancy and childbirth or in the 42 days after delivery (www.safemotherhood.org).

\section{WHY DO THEY DIE?}

Most maternal deaths can be prevented if access to appropriate health care is guaranteed when required. Maternal survival is heavily dependent on skilled care. Ensuring skilled birth attendance combined with emergency obstetric care when complications arise could eliminate $75 \%$ of maternal deaths. The obvious challenge is to gather the necessary resources to provide these health services to the whole population. Studies have repeatedly shown that the health system can fail at home, in the community or in the facility $[8,9]$.

\section{Status of Women \& Human Rights}

Considering the political, social, economic and cultural determinants [10] in women's health, we quickly understand how the choices women make and the role they play in society can affect maternal issues [11]. Women are often not in a position to decide if, when and with whom to become pregnant (Fig. 2). Exposure to unsafe sex, unwanted pregnancy, sexual violence and unsafe abortions violate a woman's right to make decisions about her own body.

Women in lower socioeconomic strata are far more likely to be denied access to life-saving interventions and to die as a result of pregnancy or childbirth. Different factors contribute to this failure to respect the right to equity, health and life. Women's health expenses are not often a priority in households where finances are traditionally managed by men. Underprivileged families who have less money tend to live further away from healthcare facilities [12]. The financing of the intervention is in some cases a barrier which may be impossible to overcome. The removal of financial barriers to delivery and emergency care is essential if MDG 5 is to be attained. In Indonesia for instance, maternal mortality is three to four times higher among women with lower economic status compared to those who are wealthy $[13,14]$.

Women commonly bear a lower social, economic and legal status; disparity and inequity between men and women are omnipresent. A woman's death is however more than a personal tragedy; her absence endangers the survival of the newborn, leaves orphans, directly affects the family means of subsistence and decreases the economic productivity of the whole community. The Women Deliver conference (London, October 2007) reminded how much it pays to invest in women. The world loses US\$15 billion in productivity by simply letting women die in childbirth while it would only cost $\$ 6$ billion to provide the health services to save their lives $[15,16]$.

\section{Insufficient and Inadequate Funding}

Donor disbursements for maternal, newborn and child health increased from US\$2.119 million in 2003 to $\$ 3.482$ million in 2006; funding for maternal and newborn health 


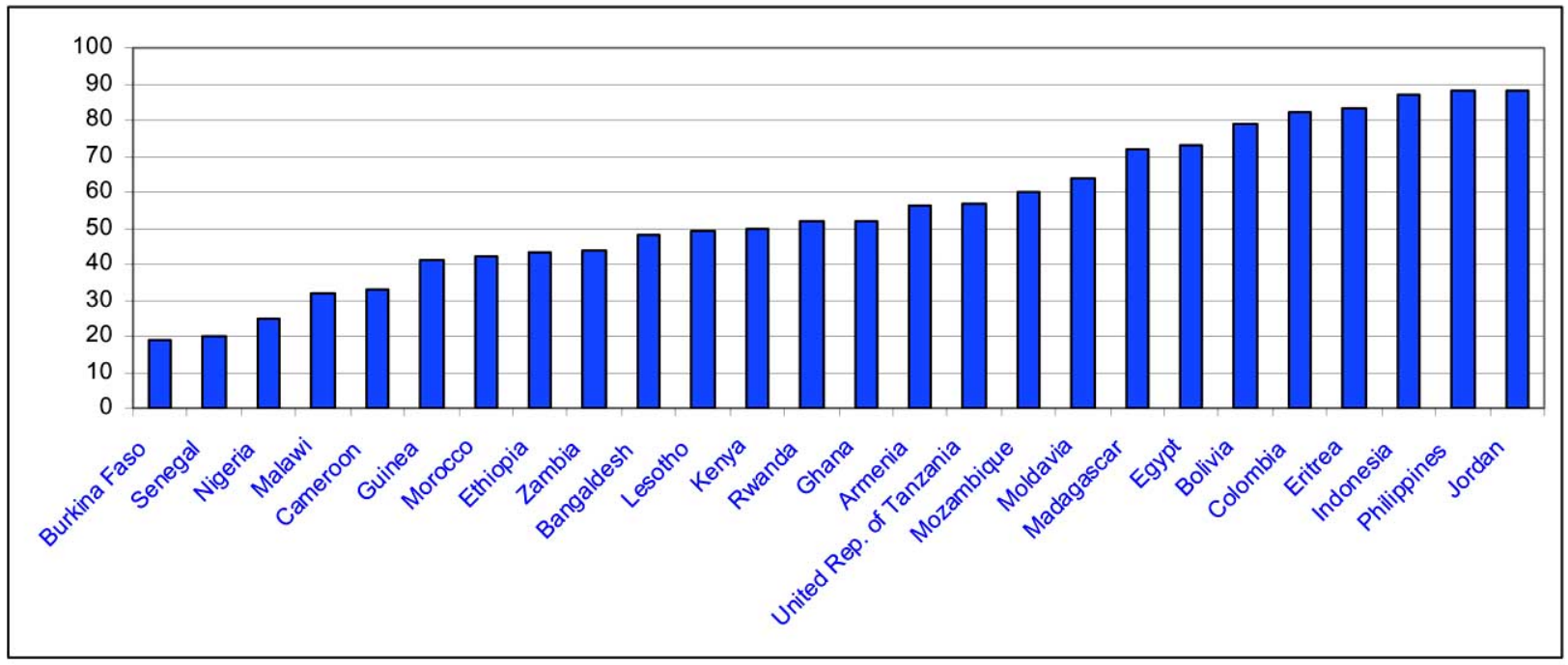

Fig. (2). Percentage of women who have a final say in decision-making regarding their own health care, 2001-2005 [11].

increased by $66 \%$. In the 68 priority countries identified by Countdown 2015, disbursements for maternal and neonatal health increased from US\$7 per live birth in 2003 to US\$12 per live birth in 2006 [17]. Additional commitments made by government representatives during 2008 (International Health Partnership, the UN General Assembly) should add to the positive trend. Although expenditures are increasing, they are still far from sufficient; supplemental investments are needed [18, 7].

Despite the Paris Declaration on Aid Effectiveness, 95\% of development assistance is still disbursed through projects rather than health sector or budget support and therefore bypasses the government systems [19]. Changing the financial support mechanisms of development assistance is no easy matter. The aid flows to recipient countries continue to fluctuate greatly due to faltering long term commitments and lack of coordination among the donors. This compromises the planning and viability of the long-term programs and investments that health system reform and strengthening require.

The deaths continue, but many governments have shown little interest in prioritizing MDG5. Why has this health issue failed to attract political priority?

Economic competition, conflicts and changes in global and national policies, and poverty reduction strategies all influence policy-makers priorities and governance in one way or another, which indirectly affects maternal health outcomes. Political stability, accountability, rule of law, regulatory capacity and control of corruption are indicators that consistently decline in importance when MMR rises [20, $21]$.

\section{ON THE AGENDA}

Since the international conference in Nairobi in 1987, maternal health has been recognized as a core component of reproductive health and has become a key theme in world health and development, at least on paper. Many international commitments and treaties have pledged to reduce maternal mortality.
The Convention on the Elimination of All Forms of Discrimination Against Women (CEDAW) adopted by the UN General Assembly in 1979 clearly asserts the reproductive rights of women. The United Nations International Conference on Population and Development (ICPD) in Cairo (1994), the World Summit for Social Development in Copenhagen (1995) and the United Nations Fourth World Conference on Women (FWCW) in Beijing (1995) affirm women's right of access to appropriate health care services in pregnancy and childbirth. In 2003, the UN Commission on Human Rights states that sexual and reproductive health are both integral elements of the right to health. The right to the "highest attainable standard of health" was already recognized in 1966 by the International Covenant on Economic, Social and Cultural Rights (art 12) [22].

In 2000, 189 member states of the UN agree upon the 8 Millennium Development Goals, their 18 targets and 48 monitoring indicators with the clear objective of providing guidance in the design and monitoring of development programs and policies, in combination with the assessment of aid effectiveness [23]. The Rome Declaration on Harmonization (February 2003) and Paris Declaration on Aid Effectiveness (March 2005) pursue the same line [24].

Under the recommendations of the UN Secretary-General in 2005, 4 additional targets and 11 indicators are endorsed by the MDG revised framework; they became effective 15 January 2008. Thereby, the fifth Millennium Development Goal, aiming to improve maternal health, saw its original target joined by an additional one, to achieve era universal access to reproductive health by 2015 [25, 26]. Universal access to reproductive health refers to the ability to achieve sexual and reproductive health (including maternal health) through health care, as defined within the Program of Action of the ICPD [27] (Table 1).

Despite these important steps, MDG5 was recognized as being the most "off track" goal by the most recent United Nations General Assembly in September 2008. A significant question which remains is: how can this be explained? 
Table 1. Revised MDG Framework [26]

\begin{tabular}{|l|l|}
\hline Goal 5 - Targets & Indicators for Monitoring Progress \\
\hline \hline $\begin{array}{l}\text { Target 5.A: Reduce by three quarters, between } \mathbf{1 9 9 0} \text { and 2015, the } \\
\text { maternal mortality ratio }\end{array}$ & $\begin{array}{l}\text { 5.1 Maternal mortality ratio } \\
5.2 \text { Proportion of births attended by skilled health personnel }\end{array}$ \\
\hline Target 5.B: Achieve, by 2015, universal access to reproductive health & $\begin{array}{l}5.3 \text { Contraceptive prevalence rate } \\
5.4 \text { Adolescent birth rate } \\
5.5 \text { Antenatal care coverage (at least one visit and at least four visits) } \\
5.6 \text { Unmet need for family planning }\end{array}$ \\
\hline
\end{tabular}

It would be a mistake to believe maternal health stakeholders have been absent, passive or unproductive.

Since the launch of the Safe Motherhood Inter Agency Group in 1987, WHO, UNFPA, UNICEF, UNDP, the World Bank and other UN agencies have worked together with many non-governmental organizations and governments in an unprecedented number of $\mathrm{MH}$ research and intervention programs funded by foundations, bilateral and multilateral aid. New structures, programs (Thematic Funds, International Health Partnership, etc.) [7] and projects have been recently created; some others are in preparation, a few public-private partnerships in embryo.

In 2005, the Partnership for Maternal, Newborn and Child Health (PMNCH), a merger of 3 existing partnerships (the Partnership for Safe Motherhood and Newborn Health, the Child Survival Partnership and the Healthy Newborn Partnership), was launched to accelerate efforts and optimize results toward achieving MDG 4 (to reduce child mortality, targeting a two thirds cut in the under-five mortality rate) and MDG 5. Its main purpose is to intensify and harmonize national, regional and global action to improve maternal, newborn and child health with concrete actions aiming to improve care to the three recipients, support research and advocate for change. The PMNCH guiding principle is based upon the continuum of care, which addresses the fact that maternal, newborn and child mortality and ill health share a number of similar and interrelated structural causes and solutions. For instance, skilled care before, during and immediately after birth reduces the risk of death or disability for both the mother and the baby.

Some perceived this global partnership, because of its wider scope and multi-target approach, as the potential leader the sector had long been waiting for. More than 3 years after its creation, opinions are divided about the role it has played so far and its ability to solve recurrent problems.

\section{DISSENSIONS \& DEFICIENCIES}

22 years after Nairobi, 1.450 women still die each day from avoidable causes.

In the late eighties, a severe knowledge gap had to be filled, since very little data was available. The output from research and programs now allow us to better understand the complex cross-cutting issue maternal health represents, a dramatic health problem which must deal with manifold and interdependent components.

Why is it that this high level of professional and active involvement has not led to more advancement? Some elements of answers:
First, measuring maternal mortality and progress in its reduction has been, and remains, a great challenge. The ability to reliably assess status and trends in maternal mortality is limited. Progress is often monitored on the basis of proxy indicators partly because, compared with infant deaths for instance, maternal deaths are less frequent events. The measurement difficulties are so formidable [28] that the debate has for long revolved around questions of measuring tools and techniques. Recently, significant advances have provided efficient mechanisms for gathering the required data [29]. At present, as the capacity to systematically count the maternal deaths nationally is still in need of strengthening, MH stakeholders have no other option than to deal with the relative uncertainty in the estimates.

A second disturbing element is competition. Organizations working in the same field are the most obvious source of competition. The multiple choices maternal health implies have not favored natural collaboration among UN agencies, nor among donors and international NGO's. Decision-makers may be guided by an overall vision and specific objectives, but competing pressures can also be decisive in determining their decisions. They all have vested interests, sensitivities and their own agendas. Consequently, this means that there is a scarcer chance of radicalism or creativity. The MNH scene could be seen as divided between some large stakeholders who could not avoid the convenience of tunnel vision and other smaller stakeholders who are either stuck with their dependant status or disempowered to make significant change happen rapidly.

Through a joint declaration, the four major UN health agencies have recently confirmed their commitment to strengthen national capacities by naming focal and partner agencies for each component of the continuum of maternal and newborn care and related areas [30].

Thirdly, numerous substantive disagreements and gaps have fragmented the directions taken and choices made.

These disputes include: prevention versus care, mother versus child, vertical initiatives versus sector-wide approach or multi-sector programs, skilled care versus community approach, traditional versus skilled birth attendance, isolated efforts versus joint collaboration, local versus central decision-making, home and community-based interventions versus facility-based care, addressing supply versus demand side, short-term versus long-term investments, focus on reproductive health or on health systems reform and strengthening. These dichotomies illustrate the challenge, as well as the difficulty, of making today's motherhood safer. The different perspectives have proven that, in addition to 
weakening undertaken actions; they are partly responsible for the lack of significant consequences for pregnant women over the last two decades. The dissensions have also undermined the Safe Motherhood Initiative and prevented clear strategic direction and leadership to guide it $[31,32]$.

Fourthly, the Partnership for Maternal Newborn and Child Health was sound out to become leader but core management issues such as communication, structure and effective leadership are yet to be resolved. Currently, even if tensions between key stakeholders remain, the field seems mature enough for more cohesion, harmonization and integration.

Now, how to expect political will and commitment to rise with no equivoque in such a convoluted context of mixed messages and underlying partisanship?

The changing environment, as a result of political and economical developments towards globalization and the repositioning of some key donors, has engendered compulsory adjustments in most non-governmental organizations, requiring focus on new remits. The MDG deadline and the expanding but still scarce resources allocated to MNH have intensified competition among countries and organizations, the pressure to occupy a distinctive place on the market, and the need to excel in order to attract both recognition and demand. But is all this of any direct benefit to dying mothers?

The factors shaping political priority for global initiatives have been identified [33]. The ability to combine them underlines the difficulty of creating and sustaining the momentum. Under international guidance, many countries have taken different routes to achieving the challenging mission of assessment, planning and implementation of Maternal Health Policies (road maps). The question now is: are those routes the best ones?

In poor countries where the available budget cannot reasonably finance all the government duties, some politicians feel the pressure to achieve quick and superficially visible results at the lowest possible cost. For instance, better delivery services in the capital and other major cities of a country could become a tempting shortcut to statistically meet the target $5 \mathrm{~A}$ at the expense of sustainable solutions in the rural areas.

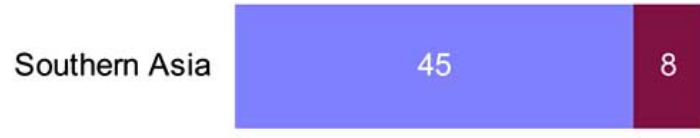

8 to clean up their act, but funders and key international and national actors, for their part, must be given an incentive to be more efficient and accountable.

\section{PROGRESS}

It helps to keep in mind the main trends. Despite longstanding efforts, very little progress has been made in saving mothers' lives [34]. Out of all the Millennium Development Goals, MDG5 is the one that has undergone the least progress $[35,36]$. A closer look confirms that it has not only been insufficient and uneven, but also especially difficult to measure.

The global maternal mortality ratio is 450 maternal deaths per 100000 live births in 2005 versus 480 in 1990 . This represents an improvement of 1 per cent per year during that period, while a yearly average decrease of 5,5 per cent is needed to reach the first target of MDG 5 [37]. The global proportion of deliveries attended by skilled health workers has gone up from $47 \%$ in 1990 to $61 \%$ in 2006.

In contrast to the first target, the indicators measuring the universal access to reproductive health are headed in a more promising direction. Antenatal care (proportion of women attended at least once during pregnancy by skilled health personnel) and the percentage of women married or in union using contraception have increased, respectively by $37 \%$ and $22 \%$ in developing countries between 1990 and 2005 [1].

The adolescent birth rate (births from 15 to 19 year old women per 1,000 women) is declining slowly, showing a $20 \%$ average in the developing countries for the same period. Even if it remains unacceptably high in low- and middleincome countries, the proportion of married women of reproductive age with unmet needs for family planning is decreasing. In Sub-Saharan Africa, $24 \%$ of women who want to delay or stop childbearing have no access to family planning (Fig. 3).

All of these crucial services, antenatal care, contraception and family planning contribute significantly to safer motherhood.

The importance of maternal mortality fluctuates not only across countries but also within them. Most vulnerable

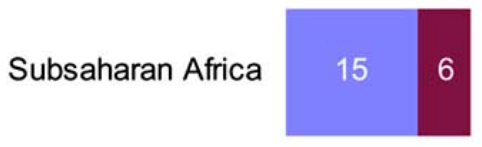

Fig. (3). Contraception Prevalence (CP) and unmet needs, 2005 (Percentage). 
populations (rural, poor, migrant and displaced) have shown the least improvement and remain the most affected.

Success stories (Bangladesh, Cuba, China, Colombia, Egypt, Honduras [38], Japan [39], Mali [40] Thailand, Malaysia [41], Mexico, Nepal, Sri Lanka [42], Vietnam,) show nevertheless that despite different initial contexts, drastic improvements are achievable; Maternal Mortality can be halved in developing countries every 7-10 years [43]. The most eloquent testimonies show how support and involvement at all levels help to deal with the various components of the MNH strategy implementation.

Impressive progress has been made these past two decades: development and communication of knowledge; greater awareness of the issue; definition of process indicators [44]; use of common indicators and job descriptions; development of instruments, packages, programs and approaches [45,46]; efficient procedures and measurements. A consensus has emerged over what the solutions are. Rationalisation is in progress but considerable work remains to be accomplished.

While 1450 women are dying every day, what is needed to accomplish substantial progress by 2015 ?

\section{SOLUTIONS}

Logic suggests that we first concentrate on the root concerns of pregnancies, particularly the unwanted ones: deficient family planning and unsafe abortion.

More than one third of the 182 million pregnancies occurring annually in the developing countries are unintended and $11 \%$ end in unsafe induced abortions. Twothirds of the unintended pregnancies occur among women who are not using any method of contraception [47, 48].

$55 \%$ of all induced abortions in developing countries are unsafe. Complications due to unsafe abortion procedures cause an estimated $13 \%$ of maternal deaths or 67.000 per year. Parallel to the core strategies targeting decline of maternal deaths, actions to reduce the number of unwanted pregnancies will have positive influence on maternal health.

When a woman pursues her pregnancy; the real focus is not only her survival but remains the desired end result, a healthy mother and baby 42 days after childbirth.

Fortunately, the tendency to name the health issue and describe it scientifically without including the political, economical and social mechanisms that ensure its genesis and transmission is now gone. However, the reduction of maternal mortality (and morbidity) is a long term effort with no single solution [49]. Solutions are as complex and hybrid as the various issues and contexts they relate to; the same strategy cannot be applied in all situations and must be able to respond to evolving environments.

Lack of information, weak health systems, lack of political commitment, gender inequities (MDG3), cultural barriers and poverty are among the main obstacles to be overcome. We will focus on three leads that intend to address these simultaneously: how to meet the specific conditions required to define and implement the best strategy in a context of health system strengthening; how to fill the leadership vacancy advantageously; and how to effectively consolidate political will and stakeholders' responsibility.

\section{STRATEGY}

The scope clearly enounced in MDG5 is maternal health. Narrowing down the maternal health issue to maternal deaths might not serve the cause. The limited attention given to the first outcome chosen to assess progress in improving maternal health is playing the role of a reducing agent. Is it necessary for a mother to die in order to justify a little attention? Over the last 20 years, more than 10 million women have died; more than 200 million have been injured and/or disabled due to pregnancy complications. The additional target - universal access to reproductive health effective since the beginning of 2008, will hopefully broaden the horizons and enhance the value and the extent of the persisting issues. It is important to ensure that the four new indicators (Table 1) which will help monitor progress are integrated into all programs and plans for the 7 coming years.

The scope of a maternal health strategy cannot be restrained to interventions during the ante, intra and postpartum period. A mothers' right to health is more than just a right to health care [50]. Many pitfalls, the trap of vertical vision, and the consequences of a non-comprehensive approach have been identified over time [32, 51-53].

In addition to improved technical solutions, adaptive intervention packages [53] have also proven their efficacy; the necessity to have both essential and emergency obstetric care is not longer questioned. Despite the complexity of the issue, a limited number of decisive choices must be made to reduce maternal mortality $[54,55]$.

To ensure sustainable maternal health services and lasting changes, the strategy (collection of coordinated solutions) addresses the whole range of causes and minimizes the difficulties in a constructive and cost-effective way. Based upon the contributions of all health services, the strategy development builds a coherent and comprehensive response to what the continuum of care [37] entails: a sum of interventions to be delivered during a woman's life-cycle. It should be critical and cautious when choosing the most adequate instruments from the exhaustive list of existing tools and methods.

Policy-makers in developing countries are mostly deprived of financial and human resources which prevents them to set up a quality health care system. The main idea here is to help national governments make the appropriate decisions with full awareness of the existing knowledge and available resources within their health systems. The appropriate core strategy must be constructed for the specific financial means they supervise (own and support budgets) and should be implemented gradually [56].

This explains why investment in data collection and use indicators that are valid, reliable and comparable is inevitable; while the international community establishes well-defined measurement strategies for monitoring progress and evaluating health programmes and systems [57]. 
Replacing the litany with facts and a methodical approach is indeed crucial for decision-makers and managers; well informed and confident, they are able to proactively address maternal health with strategic and costeffective interventions [49]. Ultimately, in order to deliver strategic decisions and considerably increase the likelihood of success, sustained improvement of maternal health must be adopted in a clear and consistent approach that displays the right qualities at the right moment while also admitting to problems and contingencies. The taking and implementation of major decisions should be planned and monitored carefully, methodically. A casual and unfocused process is likely to produce unsatisfactory results.

The implementation model should be consistent with the assumptions associated with needs assessment and the strategy and tactics to be executed. For example, there is indeed little direct effect in organizing timely transport to an emergency obstetric care for any woman in need if the blood and skilled health care workers are lacking or cannot be guaranteed on a middle term basis at the facility. Objectives must remain achievable and actions must lead to results.

The intra-disciplinary approach defines an adequate action plan that balances structural and quick win measures; the solution is to take immediate action on some health outcomes while effecting systemic change on the remainder [20]. This approach captures short term effects and directs appropriate efforts to enhance performance and long term investments.

From that perspective, it is de facto crucial to test how robust the action plan is in terms of unexpected changes in the environment. For example, a development assistance agency has postponed payment by 6 months or political instability has temporarily displaced 20.000 people. In this scenario, it is then crucial to determine the best way to adapt and implement the original solution within the changing health system.

\section{LEADERSHIP}

Too many actors have been trying to guide or influence policymaking in developing countries, with lack of cohesion and loss of performance as a consequence. Donors often dictate the rules, since most governments and organisations lack the necessary resources, mandate or full-range expertise to deal comprehensively with the maternal and neonatal health issues.

Collaborating with a sound international partner to guarantee an evidence-based decision-making process, steadier aid financial flows, reliable synergies, economies of scale and knowledge, and coordinated planned actions would help policy makers to face the overwhelming challenges they are confronted with in the developing countries. Is this a day dream, impossible to put in place in order to achieve MDG $5 ?$

The Safe Motherhood Initiative has not yet been able to remediate the lack of leadership that has undermined the tremendous efforts and advances produced over these last two decades [58]. Diversity in opinions, experiences and priorities is the healthy basis of any advancement, but discordant views need to harmonize at one point, at the risk of falling short of radical change. A higher sense of urgency is needed to achieve the required results.

With new knowledge of a wide variety of solutions, a waste of time in these circumstances becomes unacceptable; the current phase should prioritize the definition and the implementation of strategies [59] to improve maternal health and the management change it induces. As dissensions about interventions previously hampered progress, one can expect a similar scenario to occur during the current phase, again at the direct expense of the endangered mothers, if no partnership, consortium or alliance effectively takes up a regulating role with the active support of the whole $\mathrm{MNH}$ community sometime soon.

It is duty of the international $\mathrm{MNH}$ community to foster innovation and creativity in order to minimize or eliminate barriers, develop synergies between stakeholders, and enable governments to find and implement their solutions. As resources are limited, overlaps, disparate actions and funding, and lack of prioritization must be genuinely diminished.

\section{POLITICS}

How to generate much needed political support as a compulsory trigger for lasting change? How to perpetuate the attention and sense of urgency this tragedy deserves?

Thanks to concomitant persuasive advocacy campaigns, the political sphere has recently shown increased awareness and preoccupation for tragic maternal health issues.

Active at local, national and international level, the organisations engaged in advocacy relay the concerns of the communities to key decision-makers in order to improve the policies and increase funding. New financial commitments to maternal health initiatives have been announced in 2008 . This momentum must be sustained; the Rights Based Approach (RBA) is a powerful tool to consolidate it [60].

For many stakeholders, gender and reproductive rights [61] are often more theoretical than real, but international community and national governments are accountable for respecting, protecting and fulfilling the right to health by guiding policy formulation and national plans within that perspective [52].

The intrinsic role of civil society in that process should not be underestimated. Together with community based organisations, they represent and empower the rightful claimants. They are the best link to reach the most vulnerable groups (rural women, refugees, HIV positive) and it is through their actions that an integrative participatory approach becomes more concrete [46].

\section{CONCLUSIONS}

The narrow focus of assimilating maternal health to avoid deaths stigmatizes the harsh battles the Safe Motherhood Initiative has fought for twenty years to arouse attention towards the tragedy that dying mothers describes. The impressive but insufficient progress in reducing maternal mortality has left more than one perplexity. The 
difficulties in reaching any political decision with clear facts and figures, as well as antagonisms and internal competition, have impeded progress. Still chasing its old demons, the Initiative today faces new challenges.

The ineluctable complexity of this cross-cutting issue has been partially demystified and more cohesive statements about the solutions to decrease maternal mortality have been made.

There is no single magic bullet and no vaccine to test, but solutions are still known; access to family planning is key. Effective packages of $\mathrm{MNCH}$ interventions and their delivery have been identified; adequate care could avoid $75 \%$ of maternal deaths tomorrow. A greater accent has recently been given to the different social and economical determinants that affect maternal health. If well balanced, the recognized link between mothers, newborns and children does not put the " $\mathrm{M}$ " aside [62], but rather underlines the catalyst role maternal health care can play.

Maternal mortality is on the way to overcoming complacency and advancing a true sense of urgency, hopefully to achieve significant results in the coming 7 years.

As more programmes are launched and more financial means mobilized, it is still unclear what the most effective way to deal with maternal mortality and morbidity is, how it will be found, and if the right focus on sustainable results will be given. To determine the optimal use of scarce resources, involving comparisons of two or more alternatives to achieve a specific objective under the given assumptions and constraints is one definition for a systematic approach. Combined with a systemic focus, this approach might be able to develop the policy and appropriate implementation that best address the unmet needs.

Fifteen years after ICPD, our turbulent world still offers not only hazards, but also many wonderful opportunities for maternal health stakeholders to grasp. A better knowledge of and impact on sexual and reproductive health and rights - the broad scope maternal health stakeholders could claim - is one. The implementation of the national MH strategies in the context of health system strengthening is another. It is time to remove obstacles from the path to improve maternal health and focus on results, allowing for more mothers and babies to stay alive.

Further research should focus on the development of innovative systematic approaches that assess the national needs and potentials with validated tools and also determine the best combination for optimizing sustainable results.

\section{REFERENCES}

[1] Hill K, Thomas K, AbouZahr C, Walker N, Say L, Inoue M, Suzuki E. Estimates of maternal mortality worldwide between 1990 and 2005: an assessment of available data. Lancet 2007; 370: 13119.

[2] AbouZahr C, Royston E. Maternal mortality: a global factbook. Geneva: World Health Organization; 1991.

[3] Nanda G, Switlick K, Lule E. Accelerating progress towards achieving the MDG to improve maternal health. World Bank 2005.

[4] WHO Why do so many women still die in pregnancy or childbirth? Available from http://www.who.int/features/qa/index.html [Accessed on 13, January 2009].
[5] World Health Organization, UNICEF, UNFPA, World Bank Maternal mortality in 2005. World Health Organization, UNICEF, UNFPA, World Bank 2007. Available from: www.who.int/whosis/ mme_2005.pdf [Accessed on December 29, 2008].

[6] UN Millennium Project Task Force. Who's got the power? Transforming health systems for women and children. United Nations Development Programme 2005.

[7] The state of the world's children 2008: child survival. New York, United Nations Children's Fund 2008.

[8] Mills A, Rasheed F, Tollman S. Strengthening Health Systems, Disease Control Priorities in Developing Countries Available from http://files.dcp2.org/pdf/DCP/DCP03.pdf [Accessed 12 January 2009].

[9] Kruk ME, Freedman LP. Accessing health system performance in developing countries: a review of the literature. Health Policy 2008; 85: $263-276$

[10] Health Canada. Women's Health Strategy, Women's Health Bureau, Health Canada, 1999. Available from http://hc-sc.gc/english/ women/womenstrat.htm [accessed 30 December 2008].

[11] CSDH. Closing the gap in a generation: health equity through action on the social determinants of health. Final Report of the Commission on Social Determinants of Health. World Health Organization 2008.

[12] Ronsmans C, Etard J-F, Walraven G, et al. Maternal mortality and access to obstetric services in West Africa. Trop Med Int Health 2003; 8: 940-8.

[13] Graham WJ, Fitzmaurice AE, Bell JS, Cairns JA. The familial technique for linking maternal death with poverty. Lancet 2004; 363: 23-27.

[14] Richard F, Witter S, De Brouwere V , Reducing financial barriers to obstetric care in low-income countries. Studies in Health Services Organisation \& Policy 2008, 24.

[15] UNFPA. Maternal Health: Keep the Heart of the MDGs Pumping. Available from http://www.un.org/millenniumgoals/2008highlevel/ pdf/media\%20advisories/maternal\%20health.pdf [accessed 12 January 2009].

[16] Gill K, Pande R, Malhotra A. Women deliver for development. Lancet 2007; 370: 1347-57.

[17] Greco G, Powell-Jackson T, Borghi J, Mills A. Countdown to 2015: assessment of donor assistance to maternal, newborn, and child health between 2003 and 2006. Lancet 2008; 371: 1268-75.

[18] Bulletin World Health Organization 2007; 85: 256-63.

[19] Partnership for Maternal, Newborn and child Health. Countdown to 2015. The 2008 report. Tracking progress in Maternal, Newborn and Child Health UNICEF 2008.

[20] Campbell White A, Merrick TW, Yazbeck AS. Reproductive Health: the Missing Millennium Development Goal. Washington DC, World Bank 2006; pp. 3-40.

[21] Kaufman D, Kraay A, Mastruzzi M. Government Matters III: Governance Indicators for 1996-2002” World Bank 2003.

[22] Hunt P. Right to the highest attainable standard of health. Lancet 2007; 370: 369-71.

[23] MDG tables. Available from www.emro.who.int/cbi/PDF/MDG/ UNPAN012604.pdf [Accessed 7 January 2009].

[24] Aid Harmonisation \& Alignment. Available from http://www. aidharmonization.org/ah-overview/secondary-pages/why-Rome Declaration \& http://www.aidharmonization.org/ah-overview/ secondary-pages/editable?key=205 [Accessed 7 January 2009].

[25] Millennium Development Goals Report 2008. Available from http://mdgs.un.org/unsd/mdg/Host.aspx?Content=Indicators\%2fOff icialList.htm [Accessed 7 January 2009].

[26] New and Revised MDG Targets and Indicators According to the revised MDG framework, effective 15 January 2008 Available from http://www.pcbs.pna.org/Portals/_pcbs/mdgs/MDGs2008_Updates_ English.pdf [accessed 30 December 2008].

[27] Report of the International Conference on Population and Development, Cairo, 5-13 September 1994. New York, United Nations, 1994 (A/CONF.171/13; http://www.un.org/popin/icpd/ conference/offeng/poa.html, [Accessed 13 December 2008].

[28] Graham WJ, Foster LB, Davidson L, Hauke E, Campbell OM, Measuring progress in reducing maternal mortality, Best Pract Res Clin Obstet Gynaecol 2008; 22(3): 425-45.

[29] Graham WJ, Ahmed S, Stanton C, Abou-Zahr C, Campbell OM. Measuring maternal mortality: an overview of opportunities and options for developing countries BMC Med 2008; 6:12. 
[30] WHO-UNFPA-UNICEF-World Bank. Joint Country Support for Accelerated Implementation of Maternal and Newborn Continuum of Care, 2008.

[31] Shiffman J, Smith S. A protracted launch: the first two decades of the Safe Motherhood Intiative. 2006. Available from http://apha. confex.com/apha/135am/techprogram/paper_161083.htm (accessed 28 December 2008).

[32] Béhague D, Storeng K. Collapsing the Vertical-Horizontal Divide: An Ethnographic Study of Evidence-Based Policymaking in Maternal Health. Am J Pub Health 2008; 98, (4): 644-9.

[33] Shiffman J, Smith S. Generation of political priority for global health initiatives: a framework and case study of maternal mortality Lancet 2007; 370: 1370-9.

[34] United Nations Statistics Division. Millennium Development Goals indicators. Available from http://unstats.un.org/unsd/mdg/Host. aspx?Content=Products\%2fProgressReports.htm (accessed 10 January 2009)

[35] Rosenfield A, Maine D, Freedman L. Meeting MDG-5: an impossible dream? Lancet 2006; 368: 1133-35.

[36] Simwaka BN, Theobald S, Amekudzi YP, Tolhurst R. Meeting Millennium Development Goals 3 and 5. BMJ 2005; 331: 708-9.

[37] Countdown to 2015. Tracking progress in Maternal, Newborn and Child survival. Report 2008. Available from http://www.who.int/ pmnch/topics/part_publications/countdown2008report/en/index.htm $1<\mathrm{http}: / / \mathrm{www}$.who.int/pmnch/topics/part_publications/countdown 2008report/en/index.html> [Accessed 13 January 2009].

[38] Shiffman J, Stanton C, Salazar AP. The emergence of political priority for safe motherhood in Honduras. Health Policy Plan 2004; 19: 380-90.

[39] Graham WJ. Japan: setting an example to the world in reducing maternal mortality. Immpact University of Aberdeen 2008.

[40] Fournier P, Dumont A, Tourigny C, Dunkley G, Dramé S. Improved access to comprehensive emergency obstetric care and its effect on institutional maternal mortality in rural Mali. Bull World Health Organ 2009; 87: 30-38.

[41] Pathmanathan I, Liljestrand J, Martins JM, eds. Investing in maternal health in Malaysia and Sri Lanka. Washington, DC, USA: World Bank, 2003.

[42] Lakshmen Senanayake. Sri Lanka's success in improving maternal health, Arrows For Change, 2006. Available from bhttp://findarticles. com/p/articles/mi_hb019/is_/ai_n29379309 (accessed 30 December 2008).

[43] De Brouwere V, Van Lerberghe W. Safe Motherhood strategies: a review of evidence. Study in Health Services Organisation and Policy 2001; p. 17.

[44] UNICEF, WHO, UNFPA. Guidelines for monitoring the availability of emergency obstetric care, UNICEF, 1997.

[45] Nanda G, Switlick K, Lule E. Accelerating progress towards achieving the MDG to improve maternal health: a collection of promising approaches, Health, Nutrition and Population Division, Human Development Department, World Bank 2005.
[46] Howard-Grabman L, Seoane G, Davenport CA. The Warmi Project: a participatory approach to improve maternal and neonatal health. An implementor's manual 1994. Available from www.popline.org/ docs/1054/100099.html [Accessed 30 December 2008].

[47] Sedgh G, Henshaw S, Singh S, Åhman E, Shah I.Induced abortion: estimated rates and trends worldwide. Lancet 2007; 370: 1338-45.

[48] WHO, Guttmacher institute. Facts on induced abortion worldwide. WHO \& Guttmacher institute.2007.

[49] Adam T, Lim SS, Mehta S, et al. Cost effectiveness analysis of strategies for maternal and neonatal health in developing countries BMJ 2005; 331; 1107 .

[50] Sen A. Why and how is health a human right? Lancet 2008; 372: 2010.

[51] Maine D. Detours and shortcuts on the road to maternal mortality reduction. Lancet 2007; 370: 1380-82.

[52] Hunt P, Bueno de Mesquita J. Reducing maternal mortality, the contribution of the right to the highest attainable standard of health University of Essex, Human Rights Centre and UNFPA. Available from http://www.unfpa.org/upload/lib_pub_file/750_filename_ reducing_mm.pdf (accessed 15 September 2008).

[53] Kerber KJ, de Graft-Johnson JE, Bhutta ZA, et al. Continuum of care for $\mathrm{MNCH}$, from slogan to service delivery Lancet 2007; 370: 1358-69.

[54] Campbell O, Graham W, Lancet maternal survival series steering group. Strategies for reducing maternal mortality: getting on with what works. Lancet 2006; 368: 1284-99.

[55] De Brouwere V, Tonglet R, Van Lerberghe W. Strategies for reducing $\mathrm{MM}$ in developing countries: what can we learn from the history of the industrialized West? Trop Med Int Health 1998; 3 (10): 771-82.

[56] Ekman B, Pathmanathan I, Liljestrand J. Integrating health interventions for women, newborn babies, and children: framework for action Lancet 2008; 372: 990-1000.

[57] World Health Statistics 2007, WHO et al, 2007. Available from http://www.who.int/whosis/whostat2007.pdf [Accessed 30 December 2008].

[58] Lalonde A, Perron L. Enhancing the Leadership Role of Professional Associations in Maternal Health: The International Experience of SOGC 2006; 28(11): 1009-13.

[59] Freedman LP, Graham WJ, Brazier E, et al. Practical lessons from global safe motherhood initiatives: time for a new focus on implementation. Lancet 2007; 370: 1383-91.

[60] Gruskin S, Cottingham J, Martin Hilber A, Kismodi E, Lincettob O, Rosemand MJ. Using human rights to improve maternal and neonatal health: history, connections and a proposed practical approach. Bull World Health Organ 2008; 86: 589-93.

[61] World Health Organisation. Gender and reproductive rights. Available from www.who.int/reproductive-health/gender/index. html [Accessed 29 December 2008].

[62] Rosenfield A, Maine D. Maternal Mortality - a neglected tragedy. Where is the M in MCH? Lancet 1985; 2: 83-5. 